\title{
Silverfil: Its physical characterization
}

\begin{abstract}
This article focuses on the physical characterization of Silverfil (R) amalgam. Analysis of the amalgamated material semi-quantitatively showed that Silverfil (R) comprised of approximately two thirds mercury and one third silver. No other elements were detected. Examination of the amalgamated material by $\mathrm{x}$ ray mapping and metallographically showed no evidence of free mercury present. Silverfil (R) has strong affinity towards the mercury ion. X-ray Diffraction analysis showed that the amalgamated Silverfil $(\mathrm{R})$ is similar to a mineral in nature called "Moschellandsbergite". The advantages of Silverfil (R) over conventional amalgam were highlighted.
\end{abstract}
Authors:
Abu Kasim, N.H.; Yahya, N. A.; Radzi, Z.; Basirun, W. J.; Ghani,
A. A.
Journal:
3rd Kuala Lumpur International Conference on Biomedical
Engineering 2006
Year:
2007

\section{Keywords :}

amalgam; Silverfil(R); physical characterization; SELF-REPAIR; CULTURE-CONDITIONS; COMPOSITE RESIN; DENTAL PULP STEM CELL; FUNCTIONALLY GRADED DESIGN; MULTI LAYERED POST; FUNCTIONALLY GRADED DENTAL POST; SOFT SKILLS; CLINICAL PAIRING; DENTAL PULP STROMAL CELLS; LONG-TERM EXPANSION 


\section{Please cite as :}

Abu Kasim, N.H., YAHYA, N. A., RADZI, Z., BASIRUN, W. J. \& GHANI, A. A. 2007. Silverfil: Its physical characterization. In: IBRAHIM, F., OSMAN, N. A. A., USMAN, J. \& KADRI, N. A. (eds.) 3rd Kuala Lumpur International Conference on Biomedical Engineering 2006. New York: Springer.

\section{URL :}

- $\quad$ http://apps.webofknowledge.com/full_record.do?product=UA\&search_mode=GeneralSe arch\&qid=7\&SID $=$ X2b4aFj94PA75PLaLiE\&page $=1 \&$ doc $=4$

- $\quad$ http://books.google.com.my/books?id=lDQ32fqu2okC\&pg=PA134\&lpg=PA134\&dq=Its +physical+characterization+abu\&source $=$ bl\&ots=--d3iK-wM5\&sig=30zS-

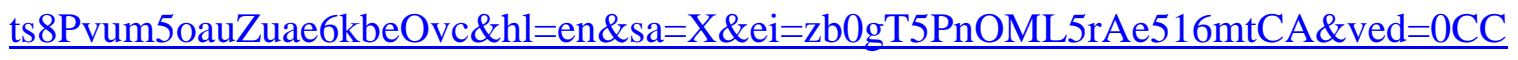
gQ6AEwAA\#v=onepage \&q=Its \%20physical\%20characterization $\% 20$ abu $\& \mathrm{f}=$ false

- $\quad$ http://www.springerlink.com/content/u0w52509q4v27351/

- $\underline{\text { http://resources.metapress.com/pdf-preview.axd?code }=u 0 w 52509 q 4 v 27351 \& \text { size=largest }}$ 